\title{
Association between Frailty Syndrome and Anemia in Community-Dwelling Elderly
}

\author{
Elisa Priscila Sousa de Assis ${ }^{1,2}$, Barbara Gazolla de Macêdo, ${ }^{1,3}$, Thais Almeida Marques da Silva1, \\ Poliana de Paula Dias Rezende' ${ }^{1}$, Érica Leandro Marciano Vieira ${ }^{4,5}$, \\ Antonio Lucio Teixeira Junior ${ }^{1}$, Carlos Maurício de Figueiredo Antunes ${ }^{1 *}$
}

\author{
${ }^{1}$ Laboratório de Epidemiologia, Programa de Pós-graduação Stricto Sensu em Medicina e Biomedicina, Instituto de Ensino e \\ Pesquisa da Santa Casa de Belo Horizonte, Belo Horizonte, Brasil \\ ${ }^{2}$ Fundação Hospitalar do Estado de Minas Gerais (FHEMIG), Hospital Regional de Barbacena, Fisioterapia Respiratória, \\ Barbacena, Brasil \\ ${ }^{3}$ Departamento de Fisioterapia, Instituto da Previdência dos Servidores do Estado de Minas Gerais (IPSEMG), \\ Belo Horizonte, Brasil \\ ${ }^{4}$ Laboratório Interdisciplinar de Investigação Médica, Faculdade de Medicina, Universidade Federal de Minas Gerais (UFMG), \\ Belo Horizonte, Brasil \\ ${ }^{5}$ Centre of Addiction and Mental Health (CAMH), Toronto, Canada \\ Email: *antunesc@santacasabh.org.br
}

How to cite this paper: de Assis, E.P.S., de Macêdo, B.G., da Silva, T.A.M., de Paula Dias Rezende, P., Vieira, É.L.M., Junior, A.L.T. and de Figueiredo Antunes, C.M. (2019) Association between Frailty Syndrome and Anemia in Community-Dwelling Elderly. Advances in Aging Research, 8, 75-87. https://doi.org/10.4236/aar.2019.85006

Received: July 14, 2019

Accepted: September 9, 2019

Published: September 12, 2019

Copyright $\odot 2019$ by author(s) and Scientific Research Publishing Inc. This work is licensed under the Creative Commons Attribution International License (CC BY 4.0).

http://creativecommons.org/licenses/by/4.0/

\section{c) (i) Open Access}

\begin{abstract}
Frailty is an important and complex phenomenon in the fields of geriatrics and gerontology and a highly relevant topic. Frailty syndrome (FS) is a multidimensional clinical condition characterized by loss of physiological and cognitive reserves across multiple organ systems. The Fried frailty phenotype is the main model used to categorize FS. Recent studies have shown an association between anemia, low hemoglobin concentration and frailty. This study aimed to assess the association between FS and anemia in community-dwelling elderly. An observational cross-sectional design was used, with 308 elderly subjects. Most participants were women (78.2\%) between 60 and 69 years old (50.6\%). The average schooling level was 9.7 years. Anemia was detected in $9.7 \%$ of participants. The frequency of frailty, pre-frailty and non-frailty was 8.2, 74.0 and $17.8 \%$, respectively. The multivariate ordinal logistic regression model identified low levels of brain-derived neurotrophic factor (BDNF) $(\mathrm{OR}=$ $0.9,95 \% \mathrm{CI}=0.9 ; 0.9)$ as risk factor associated with FS. No significant association was found between frailty and anemia. Moreover, FS may be influenced by low schooling levels, despite the non-significant result obtained in the statistical model. These findings contribute to elucidating other factors associated with FS, especially in community-dwelling elderly.
\end{abstract}

\section{Keywords}

Anemia, Frailty, Elderly 


\section{Introduction}

Population aging is one of the most widely discussed phenomena worldwide. According to the World Health Organization (WHO), a seven to eight-fold increase in the elderly population is expected in developing countries. In Brazil, it is estimated that 30 million inhabitants will be aged 60 or older in 2020 , that is, $13 \%$ of the population, and by 2050 , life expectancy will be close to 82 years, corresponding to $28 \%$ of the population [1] [2].

The growing number of elderly individuals in the Brazilian population has caused a shift in the demographic and epidemiological profile and the emergence of a new and challenging health paradigm: functional disability, dependence and loss of autonomy [3] [4].

In this context, frailty syndrome (FS) is one of the most problematic phenomena in the elderly population. The different definitions of FS make it difficult to standardize universally accepted criteria for healthcare professionals [5] [6] [7]. The most recent concepts define frailty as a multidimensional clinical syndrome characterized by a decline in physiological reserves.

In short, FS involves a triad of age-related changes, namely sarcopenia, neuroendocrine dysregulation and immunological dysfunction [5]. Underlying biological factors of the syndrome include dysregulation of inflammatory processes, leading to increased expression of inflammatory markers.

The primary model used to characterize FS is the frailty phenotype, created based on data from the Cardiovascular Health Study (CHS) by Fried and collaborators [5], consisting of five biological criteria: unintentional weight loss in the last year, reduced grip strength, slow gait, exhaustion and low physical activity. However, socio-economic and nutritional factors and the presence of comorbidities such as anemia should also be considered in order to better understand frailty [5].

Anemia has been associated with a decline in functional capacity and frailty in community-dwelling elderly. Some studies have linked low hemoglobin concentrations to a higher incidence of FS in the elderly [8].

Anemia and frailty syndrome seem to share the same pathophysiology of inflammation [9]. The rise in inflammatory mediators during aging can interfere in hematopoiesis, altering red blood cell formation and resulting in anemia of inflammation [10]. On the other hand, this increase can exacerbate oxidative stress, contributing to the development of comorbidities and frailty syndrome [9] [11]. There is no consensus in the literature regarding whether anemia leads to frailty or vice versa, or if the two conditions develop together.

Thus, understanding the factors that contribute to the emergence of FS may improve quality of life and independence, resulting in lower costs for the healthcare system. As such, this study aimed to assess the possible association between FS and anemia in community-dwelling elderly and identify indicators that may be related to other physical and immunological factors.

\section{Patients and Methods}

This is a cross-sectional observational study with 308 elderly participants selected 
at a physiotherapy outpatient clinic, in the period from 2013 to 2014. The project was approved by the institutional Ethics Committee under protocol CEP $067 / 2010$.

The sample size estimated for the study was established using the following parameters: 1$)$ type I error probability $(\alpha)$ equivalent to $0.05 ; 2)$ a power for the statistical tests of $(1-\beta)=0.90$; and 3$)$ a prevalence of frailty in cases and controls of $50 \%$ and $30 \%$, respectively (Fleiss method with continuity correction). Under these conditions, the sample size estimated was 300 participants.

The inclusion criteria were age 60 years or older, able to walk independently without orthoses, agreeing to take part in the study and providing written informed consent. Exclusion criteria were having undergone surgery in the last six months, being diagnosed with cancer, sequelae from neurological diseases that affect mobility, hip and knee replacements, rheumatic diseases, and severe or decompensated heart failure.

All the participants were assessed for approximately 120 minutes and then referred for blood and laboratory tests.

\subsection{Clinical and Sociodemographic Data}

Data on sex, age, skin color, marital status and household income, occupation, schooling, physical activity level, number of drugs taken and the presence of morbidities were collected using a questionnaire compiled by the researchers.

\subsection{Anthropometric Data}

Body mass index (BMI) and height were measured to determine the cutoff points used to classify FS.

\subsection{Variables Indicative of Frailty Syndrome}

Frailty was evaluated based on the phenotype proposed by Fried and collaborators [5], consisting of five criteria: 1) unintentional weight loss, assessed using the question "have you lost more than $4.5 \mathrm{~kg}$ unintentionally? (that is, without diet or exercise). If the answer was yes, the subject was classified as frail for the weight loss criterion [5];2) exhaustion was determined based on two items from the Center for Epidemiologic Studies Depression Scale (CES-D): "During the past week I felt that everything I did was an effort" and "During the past week I could not get things done". Participants classified as frail based on exhaustion were those who answered "frequently" or "always" to either of these two items [5]; 3) physical activity level was assessed by the Active Australia Questionnaire (AAQ-Brazilian version); 4) muscular strength was evaluated by measuring grip strength with a dynamometer (Saehan SH5001). The test was conducted in line with American Society of Hand Therapists (ASHT) recommendations [12]. The cutoff points used to classify frail elderly based on muscular strength were those proposed by Fried and collaborators [5], according to BMI and sex; 5) gait speed was analyzed using the 4-meter walk test and the cutoff points for FS clas- 
sification were those suggested by Fried and collaborators [5], adjusted for sex and height.

Algorithms were created for four of the five criteria (exhaustion, physical activity, muscular strength and gait speed) using EpiInfo software (version 3.5.4, 2012) and the original cutoff points proposed by Fried and collaborators [5].

Participants who met three or more of the criteria were classified as frail, one or two as pre-frail, and none of the criteria as non-frail.

\subsection{Laboratory Tests}

A complete blood count, creatinine blood test and C-reactive protein (CRP) were performed in a commercial laboratory, and Interleukin-6 (IL-6) and BrainDerived Neurotrophic Factor (BDNF) were analyzed at the institutional laboratory. World Health Organization (WHO) criteria and reference values (hemoglobin $<12 \mathrm{~g} / \mathrm{dL}$ for women and $<13 \mathrm{~g} / \mathrm{dL}$ for men) were used to diagnose anemia [13].

\subsection{Statistical Analysis}

The elderly participants were classified as frail, pre-frail and non-frail based on the frailty criteria. Descriptive and bivariate analyses were performed to compare the groups. In order to identify potential risk factors, all variables with a p-value up to 0.30 were included in the multivariate regression model. Variables that did not meet this criterion but are considered important for frailty, according to the literature, were also selected.

Ordinal logistic regression was applied. Likelihood ratio tests were used to adjust the models. The strength of association was determined by the odds ratio (OR), with a $95 \%$ confidence interval (CI).

The STATA statistical program was used (version 14.0, Stata Corporation, College Station, TX, USA).

\section{Results}

Participants were 308 elderly individuals, with a mean age of $70.6( \pm 6.8)$ years. Most were women $(78.2 \% ; \mathrm{n}=241)$, aged 60 to 69 years $(50.6 \%, \mathrm{n}=156)$, and the average schooling level was $9.7( \pm 4.9)$ years (Table 1$)$.

The presence of at least one morbidity was reported by $92.5 \%$ of the sample. The most common morbidities were systemic hypertension $(69.7 \%)$, rheumatic diseases $(45.3 \%)$, dyslipidemia (38.8\%), diabetes mellitus (18.6\%), thyroid diseases $(16.0 \%)$, and depression (14.3\%). The frequency of anemia in the sample was $9.7 \%$. Frequencies for frailty, based on the categories used, are described in Table 2, and the laboratory tests are shown in Table 3.

The following variables were selected for the initial ordinal logistic regression model, which evaluated frailty in 3 categories: schooling (no. of years), number of drugs taken, anemia, dyslipidemia, depression, smoking, BDNF, IL6 and CRP (Table 4). 
Table 1. Sociodemographic, economic and behavioral aspects-frailty syndrome, Belo Horizonte.

\begin{tabular}{|c|c|c|c|c|}
\hline \multirow{3}{*}{ Variable } & \multirow{2}{*}{\multicolumn{2}{|c|}{$\begin{array}{l}\text { Frequency } \\
(n=308)\end{array}$}} & \multirow{2}{*}{\multicolumn{2}{|c|}{ Loss/Ignored }} \\
\hline & & & & \\
\hline & $\mathbf{n}$ & $\%$ & $\mathrm{n}$ & $\%$ \\
\hline \multicolumn{5}{|l|}{ Sex } \\
\hline Male & 67 & 21.8 & & \\
\hline Female & 241 & 78.2 & & \\
\hline \multicolumn{5}{|l|}{ Continuous Age (Years) } \\
\hline Mean (SD) & \multicolumn{2}{|c|}{$70.6(6.8)$} & & \\
\hline Median (IQR) & \multicolumn{2}{|c|}{$69.0(66.0 ; 75.0)$} & & \\
\hline \multicolumn{5}{|l|}{ Categorized Age (Years) } \\
\hline $60-69$ & 156 & 50.6 & & \\
\hline $70-79$ & 117 & 38.0 & & \\
\hline $80-94$ & 35 & 11.4 & & \\
\hline \multicolumn{5}{|l|}{ Retired } \\
\hline No & 30 & 9.7 & & \\
\hline Yes & 278 & 90.3 & & \\
\hline Marital Status & & & 124 & 55.9 \\
\hline Married & 129 & 41.9 & & \\
\hline Single & 53 & 17.2 & & \\
\hline Widow(er) & 83 & 26.9 & & \\
\hline Divorced/separated & 43 & 14.0 & & \\
\hline Schooling (in Years) & & & 6 & 1.9 \\
\hline Mean (SD) & \multicolumn{2}{|c|}{$9.7(4.9)$} & & \\
\hline Median (IQR) & \multicolumn{2}{|c|}{$10.0(5.0 ; 12.0)$} & & \\
\hline Categorized Schooling Level (in Years) & & & 6 & 1.9 \\
\hline $0-4$ & 67 & 22.2 & & \\
\hline $5-11$ & 127 & 42.0 & & \\
\hline $12-16$ & 80 & 26.5 & & \\
\hline $17-28$ & 28 & 9.3 & & \\
\hline Income (in Brazilian Reals) & & & 125 & 40.5 \\
\hline Mean (SD) & & 42.6) & & \\
\hline Median (IQR) & 2000 & 4000.0) & & \\
\hline \multicolumn{5}{|l|}{ Hospitalizations (Last Year) } \\
\hline None & 264 & 85.7 & & \\
\hline One & 38 & 12.3 & & \\
\hline More than one & 6 & 2.0 & & \\
\hline \multicolumn{5}{|l|}{ Number of Drugs Taken } \\
\hline None & 23 & 7.5 & & \\
\hline One or two & 98 & 31.8 & & \\
\hline Three to five & 187 & 60.7 & & \\
\hline
\end{tabular}




\section{Continued}

\section{Falls (Last Year)}

$\begin{array}{lll}\text { No } & 177 & 57.5 \\ \text { Yes } & 131 & 42.5\end{array}$

Falls (Number of Times)

$\begin{array}{lll}\text { None } & 177 & 57.5 \\ \text { One } & 75 & 24.3 \\ \text { Two } & 32 & 10.4 \\ \text { More than two } & 24 & 7.8\end{array}$

SD: Standard Deviation, IQR: Interquartile Range.

Table 2. Morbidities and frailty syndrome, Belo Horizonte.

\begin{tabular}{|c|c|c|c|c|}
\hline \multirow{3}{*}{ Variable } & \multirow{2}{*}{\multicolumn{2}{|c|}{$\begin{array}{l}\text { Frequency } \\
(n=308)\end{array}$}} & \multirow{2}{*}{\multicolumn{2}{|c|}{ Loss/Ignored }} \\
\hline & & & & \\
\hline & $\mathbf{n}$ & $\%$ & $\mathbf{n}$ & $\%$ \\
\hline \multicolumn{5}{|l|}{ Morbidities } \\
\hline Presence of at least one morbidity & 285 & 92.5 & & \\
\hline Hypertension & 214 & 69.7 & 1 & 0.3 \\
\hline Rheumatic diseases & 139 & 45.3 & 1 & 0.3 \\
\hline Dyslipidemia & 119 & 38.8 & 1 & 0.3 \\
\hline Diabetes mellitus & 57 & 18.6 & 1 & 0.3 \\
\hline Thyroid diseases & 49 & 16.0 & 1 & 0.3 \\
\hline Depression & 44 & 14.3 & 1 & 0.3 \\
\hline Anemia & 29 & 9.7 & 9 & 2.9 \\
\hline Smoker (current) & 17 & 5.5 & & \\
\hline Others & 90 & 29.3 & 1 & 0.3 \\
\hline \multicolumn{5}{|c|}{ Frailty Syndrome-Three Categories } \\
\hline Non-frail & 52 & 17.8 & & \\
\hline Pre-frail & 216 & 74.0 & 16 & 5.2 \\
\hline Frail & 24 & 8.2 & & \\
\hline
\end{tabular}

Table 3. Laboratory tests-frailty syndrome, Belo Horizonte.

\begin{tabular}{|c|c|c|c|c|}
\hline \multirow{3}{*}{ Variable } & \multirow{2}{*}{\multicolumn{2}{|c|}{$\begin{array}{l}\text { Frequency } \\
\mathrm{n}=(308)\end{array}$}} & \multirow{2}{*}{\multicolumn{2}{|c|}{ Loss/Ignored }} \\
\hline & & & & \\
\hline & $\mathrm{n}$ & $\%$ & $\mathbf{n}$ & $\%$ \\
\hline $\mathrm{BDNF}(\mathrm{pg} / \mathrm{mL})$ & & & 14 & 4.5 \\
\hline Mean (SD) & \multicolumn{2}{|c|}{$13,150.5(3698.3)$} & & \\
\hline Median (IQR) & \multicolumn{2}{|c|}{$13,243.6(10,551.4 ; 15,703.7)$} & & \\
\hline Creatinine (mg/dL) & & & 15 & 4.8 \\
\hline Mean (SD) & \multicolumn{2}{|c|}{$0.8(0.2)$} & & \\
\hline Median (IQR) & \multicolumn{2}{|c|}{$0.7(0.6 ; 0.9)$} & & \\
\hline
\end{tabular}




\section{Continued}

\section{Altered Creatinine (mg/dL) \\ (Reference Value by Sex)}

$\begin{array}{lrr}\text { No } & 227 & 77.5 \\ \text { Yes } & 66 & 22.5\end{array}$

$\mathrm{MCH}(\mathrm{pg})$

Mean (SD)

Median (IQR)

MCV (fL)

Mean (SD)

Median (IQR)

Red blood Cell Count $\left(\mathrm{mm}^{3}\right)$

Mean (SD)

Median (IQR)

Hematocrit (\%)

Mean (SD)

Median (IQR)

Hemoglobin $(\mathrm{g} / \mathrm{dL})$

Mean (SD)

Median (IQR)

IL6 (pg/mL)

Mean (SD)

Median (IQR)

White Blood Cell Count $\left(\mathrm{mm}^{3}\right)$

Mean (SD)

Median (IQR)

CRP (mg/L)

Mean (SD)

Median (IQR)
9

$29.7(1.7)$

$29.8(28.7 ; 30.9)$

$89.6(4.7)$

$89.8(86.3 ; 92.9)$

$4,521,337.8(386,803.6)$

$4,490,000.0(4,240,000.0 ; 4,750,000.0)$

9

$40.4(3.1)$

$40.4(38.3 ; 42.3)$

2.9

$13.4(1.1)$

$13.3(12.7 ; 14.0)$

14

4.5

4.0 (4.9)

$2.6(0.8 ; 5.0)$

9

$6783.3(1744.7)$

$6720.0(5600.0 ; 7900.0)$

15

4.8

BDNF: Brain-Derived Neurotrophic Factor; MCH: Mean Corpuscular Hemoglobin; MCV: Mean Corpuscular Volume; IL6: Interleukin-6; CRP: C-Reactive Protein; SD: Standard Deviation; IQR: Interquartile Range.

Table 4. Variables selected for the initial ordinal logistic regression model-frailty syndrome, Belo Horizonte, Minas Gerais.

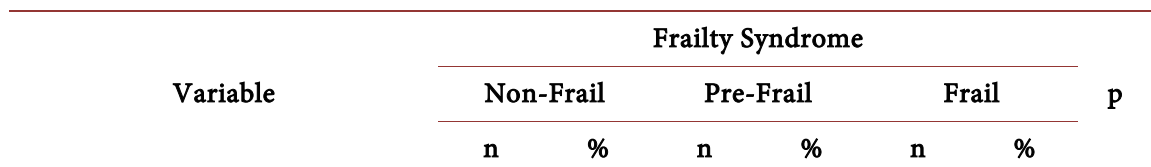

Sociodemographic, Economic and Behavioral Characteristics

Schooling (No. of Years) $(n=287)$

$\begin{array}{lcrrrrr}\mathrm{n}-\% & 52 & 18.1 & 212 & 73.9 & 23 & 8.0 \\ \text { Median (IQR) } & 10.0(6.5 ; 15.0) & 10.0(5.0 ; 12.0) & 8.0(4.0 ; 12.0) & 0.35^{\mathrm{a}}\end{array}$




\section{Continued}

Number of Drugs Taken $(n=292)$

$\begin{array}{lccccccc}\text { None } & 2 & 3.8 & 19 & 8.8 & 2 & 8.3 & \\ \text { One or two } & 16 & 30.8 & 75 & 34.7 & 3 & 12.5 & 0.14^{\mathrm{b}} \\ \text { Three or more } & 34 & 65.4 & 122 & 56.5 & 19 & 79.2 & \end{array}$

Morbidities

Anemia $(\mathrm{n}=288)$

$\begin{array}{lccccccc}\text { No } & 43 & 84.3 & 197 & 92.1 & 19 & 82.6 & \\ \text { Yes } & 8 & 15.7 & 17 & 7.9 & 4 & 17.4 & \end{array}$

Dyslipidemia $(\mathrm{n}=292)$

$\begin{array}{llllllll}\text { No } & 32 & 61.5 & 137 & 63.4 & 11 & 45.8 & \\ \text { Yes } & 20 & 38.5 & 79 & 36.6 & 13 & 54.2 & 0.24^{\mathrm{b}}\end{array}$

Self-Reported Depression $(\mathrm{n}=292)$

$\begin{array}{lccccccc}\text { No } & 47 & 90.4 & 186 & 86.1 & 17 & 70.8 & 0.07^{\mathrm{b}} \\ \text { Yes } & 5 & 9.67 & 30 & 13.9 & 7 & 29.2 & \end{array}$

Smoker (Current) $(\mathrm{n}=292)$

$\begin{array}{cccccccc}\text { No } & 51 & 98.1 & 201 & 93.1 & 23 & 95.8 & \\ \text { Yes } & 1 & 1.9 & 15 & 6.9 & 1 & 4.2 & 0.28^{\text {b }}\end{array}$

Laboratory Tests

$\operatorname{BDNF}(\mathrm{pg} / \mathrm{mL})(\mathrm{n}=283)$

$\begin{array}{lrrrrrr}\mathrm{n}-\% & 50 & 17.7 & 210 & 74.2 & 23 & 8.1 \\ \text { Mean (SD) } & 14,431.3 & (2870.9) & 12,825.6 & (3758.3) & 12,482.5 & (4124.3)\end{array}$ l.01 $^{\text {c* }}$

$\operatorname{IL6}(\mathrm{pg} / \mathrm{mL})(\mathrm{n}=283)$

$\begin{array}{llrlrrrr}\text { n - \% } & 50 & 17.7 & 210 & 74.2 & 23 & 8.1 & \\ \text { Median (IQR) } & 3.2(1.1 ; 7.5) & 2.5(0.8 ; 4.6) & 3.0(0.9 ; 5.9) & 0.17^{\mathrm{a}}\end{array}$

$\mathrm{CRP}(\mathrm{mg} / \mathrm{L})(\mathrm{n}=282)$

\begin{tabular}{|c|c|c|c|c|}
\hline $\mathrm{n}-\%$ & 17.7 & 74.1 & 8.2 & \\
\hline Median (IQR) & $1.0(0.5 ; 4.4)$ & $2.3(0.8 ; 5.0)$ & $3.3(1.3 ; 6.0)$ & \\
\hline
\end{tabular}

BDNF: Brain-derived Neurotrophic Fator; IL6: Interleukin-6; CRP: C-Reactive Protein; SD: Standard Deviation; IQR: Interquartile Range. Tests were carried out to analyze normal distribution (Shapiro-Wilk) and homogeneity between variances (Bartlett) in order to determine which test to use (parametric or nonpara-

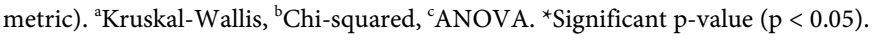

The variables schooling (no. of years) $(\mathrm{OR}=0.9 ; 95 \% \mathrm{CI} 0.9-1.0)$ and BDNF $(\mathrm{OR}=0.9 ; 95 \% \mathrm{CI} 0.9$ - 0.9) were maintained in the final ordinal logistic regression model. The $\mathrm{p}$-value for schooling was non-significant $(\mathrm{p}=0.07)$, but it remained in the final model because it was considered an important variable for model fitting (Table 5).

A chi-squared test for trend with the variable BDNF obtained a significant $\mathrm{p}$-value $(\mathrm{p}=0.01)$ and showed an inverse relationship with FS, that is, BDNF levels declined as the elderly became more frail. 
Table 5. Final model: multivariate ordinal logistic regression model, Belo Horizonte, Minas Gerais.

\begin{tabular}{cccc}
\hline Variables & $\begin{array}{c}\text { Crude Odds Ratio } \\
(95 \% \mathrm{CI})\end{array}$ & $\begin{array}{c}\text { Adjusted Odds Ratio } \\
(95 \% \mathrm{CI})\end{array}$ & $\mathrm{p}$ \\
\hline Schooling (No. of Years) & $0.9(0.9 ; 1.0)$ & $0.9(0.9 ; 1.0)$ & 0.07 \\
BDNF & $0.9(0.9 ; 1.0)$ & $0.9(0.9 ; 0.9)$ & $0.01^{*}$ \\
\hline
\end{tabular}

BDNF: Brain-Derived Neurotrophic Factor, CI: Confidence Interval. ${ }^{\star}$ Significant $p$-value $(\mathrm{p}<0.05)$. Log likelihood $=-198.48598 /$ Number of observations $=278 /$ Pseudo $\mathrm{R} 2=0.0238$.

\section{Discussion}

This study aimed to assess the association between FS and anemia in community-dwelling elderly; however, no correlation was observed. Frailty was associated with low BDNF levels. Although schooling (measured in years) exhibited a non-significant $p$-value, it was maintained in the final models because of its good statistical fit. As an indicator of socioeconomic status, it is suggested that schooling is linked to FS in the elderly.

The wide variety of instruments and criteria used to define frailty in community-dwelling elderly lead to discrepancies and non-comparable results regarding the prevalence of this syndrome [5] [14]. The present study used the criteria and cutoff points established by Fried and collaborators [5]. However, the Minnesota Leisure Time Activity questionnaire originally used to assess physical activity level was replaced with the Active Australia Questionnaire-AAQ (Brazilian version). Although the Brazilian version of the Minnesota Leisure Time Activity questionnaire shows good reproducibility and strong inter- and intra-rater agreement, it is lengthy and not specific to the elderly population [15]. Leopoldino [16] used the AAQ to assess physical activity level for the frailty phenotype in community-dwelling elderly and obtained results similar to those recorded with the Minnesota Leisure Time Activity questionnaire.

In the present study, the frequency of FS was $8.2 \%$, a finding similar to that of other studies that also used the phenotype proposed by Fried and collaborators [5], with cutoff points adjusted to the population analyzed [17] [18] [19]. However, the frequency of elderly subjects classified as pre-frail was high (74\%). A study in northern Brazil reported a $17.1 \%$ prevalence of pre-frail elderly and another, affiliated with the "Health, well-being and aging (SABE) project", 21\% to $48 \%$ [14] [20]. Although these values differ, they are still considered high for a pre-frail group when compared to other studies. Adjustments and changes to the original cutoff points may result in differences in the prevalence of pre-frailty. This study used the same operationalization of the frailty phenotype and the original cutoff points.

The frequency of anemia in the sample was 9.7\%. In Brazil, research on anemia in community-dwelling elderly is scarce, with prevalence ranging from $8.8 \%$ to $10.2 \%$, for example [21] [22]. The variation in anemia prevalence in different regions of the country can be explained by cultural and economic differences, also related to diet and nutrition. Moreover, some populations receive healthcare 
subsidies from the government and therefore have greater access to medical care. One example is a cohort from Minas Gerais state, in which anemia was prevalent in $4.5 \%$ of the elderly population, an even smaller value when compared to our results and those of other investigations [23].

No significant association was found between FS and anemia in this study. The sample consisted primarily of non-anemic subjects, with only $7.9 \%$ (17) of the pre-frail group exhibiting anemia. The absence of this association contrasts with several studies conducted in Brazil and other countries [9] [24] [25]. However, all of these used different instruments to assess FS and did not apply all the Fried and collaborators [5], changing some or adding others. There are several possible reasons for the lack of association between frailty and anemia, such as: 1) being unable to identify the anemia subtypes or stage (chronic or acute);2) the small number of anemic elderly in the study sample, and 3) the fact that most participants were functionally independent.

Low BDNF levels were associated with pre-frailty and frailty $(\mathrm{p}<0.05)$, as confirmed by the chi-squared test for trend $(p=0.01)$, indicating that BDNF levels tend to decline as the individual becomes more frail. This corroborates the findings of Coelho and collaborators [26], who studied 48 community-dwelling individuals and observed a significant difference between the pre-frail and frail groups for BDNF content, with lower levels in the former. Low BDNF content has been linked to a high risk of mortality, neurological diseases, depression and aging. Our results suggest that BDNF may be a pathophysiological factor of FS.

No significant association was found between the variable schooling and the frailty outcome. This result corroborates studies conducted by Fried and collaborators [5] and Pegorarib and Tavares [27], in which elderly classified as frail also exhibited low schooling levels, albeit with no significant difference. Despite the non-significant $\mathrm{p}$-value obtained for schooling, it was retained in the final models as an adjustment variable. An inverse relationship was observed with FS, whereby the lower the schooling level, the greater the chance of the elderly individual becoming frail. Tavares and collaborators [28] found that higher schooling levels are associated with better living conditions and well-informed individuals with greater access to healthcare. Low schooling may be linked to a number of stressors that could lead to the emergence of morbidities such as depression in community-dwelling elderly.

\section{Conclusion}

The results of this study demonstrate no association between FS and anemia; however, low BDNF levels correlated with pre-frail and frail elderly. Furthermore, we suggest that FS is influenced by low schooling levels (in years). These findings highlight the need for further research to better understand the mechanisms that contribute to frailty in the elderly. Additionally, researchers should standardize the criteria and instruments used to define FS in order to better interpret the results. 


\section{Conflicts of Interest}

The authors have declared that no competing interests exist.

\section{References}

[1] Veras, R. (2009) Population Aging Today: Demands, Challenges and Innovations. Revista de Saude Publica, 43, 1-7. https://doi.org/10.1590/S0034-89102009000300020

[2] Instituto Brasileiro de Geografia e Estatística (IBGE) (2016) Mortality in Brazil. https://ibge.gov.br

[3] Alves, L.C., Limann, B.C.Q., Vasconcelos, M.E.L., Carvalho, M.S., Vasconcelos, A.G.G., Fonseca, T.C.O., Lebrão, M.L. and Laurenti, R. (2007) The Effect of Chronic Diseases on Functional Status of the Elderly Living in the City of São Paulo, Brazil. Cadernos de Saúde Pública, 23, 1924-1930. https://doi.org/10.1590/S0102-311X2007000800019

[4] Brito, M.C.C., Freitas, C.A.S.L., Mesquita, K.O. and Lima, G.K. (2013) Aging Population and the Challenges for Public Health: Review of Scientific Production. Revista Kairós: Gerontologia, 16, 161-178.

https://revistas.pucsp.br/kairos/article/view/18552/13738

[5] Fried, L.P., Tangen, C.M., Walston, J., Newman, A.B., Hirsch, C., Gottdiener, J., Seeman, T., Tracy, R., Kop, W.J., Burke, G. and Mcburmie, M.A. (2001) Frailty in Older Adults: Evidence for a Phenotype. The Journals of Gerontology, 56A, M146-M157. https://doi.org/10.1093/gerona/56.3.M146

[6] Clegg, A., Young, J., Iliffe, S., Rikkert, M.O. and Rockwood, K. (2013) Frailty in Older People. The Lancet, 381, 752-762. https://doi.org/10.1016/S0140-6736(12)62167-9

[7] Arantes, P.M.M., Alencar, M.A., Dias, R.C., Dias, J.M.D.D. and Pereira, L.S.M. (2009) Physical Therapy Treatment on Frailty Syndrome: Systematic Review. Revista Brasileira de Fisioterapia, 13, 365-375. https://doi.org/10.1590/S1413-35552009005000061

[8] Röhrig, G. (2016) Anemia in the Frail, Elderly Patient. Clinical Interventions in Aging, 11, 319-326. https://doi.org/10.2147/CIA.S90727

[9] Corona, L.P., Andrade, F.C.D., Duarte, Y.A.O. and Lebrao, M.L. (2015) The Relationship between Anemia, Hemoglobin Concentration and Frailty in Brazilian Older Adults. The Journal of Nutrition, Health \& Aging, 19, 935-940. https://doi.org/10.1007/s12603-015-0502-3

[10] Bosco, R.M., Assis, E.P.S., Pinheiro, R.R., Queiroz, L.C.V., Pereira, L.S.M. and Antunes, C.M.F. (2013) Anemia and Functional Capacity in Elderly. Cadernos de Saúde Pública, 29, 1322-1332. https://doi.org/10.1590/S0102-311X2013000700007

[11] Assis, E.P.S., Macêdo, B.G., Oliveira, H.S.C., Rezende, P.P. and Antunes, C.M.F. (2018) Anemia and the Frailty Syndrome amongst the Elderly Living in the Community: A Systematic Review. Revista Brasileira de Geriatria e Gerontologia, 21, 229-237. https://doi.org/10.1590/1981-22562018021.170100

[12] Figueiredo, I.M., Sampaio, R.F., Mancini, M.C., Silva, F.C.M. and Souza, M.A.P. (2007) Test of Grip Strength Using the Jamar Dynamometer. Revista Acta Fisiátrica, 14, 104-110. https://doi.org/10.5935/0104-7795.20070002 http://www.revistas.usp.br/actafisiatrica/article/view/102799

[13] World Health Organization (WHO) (2019) Anemia Diagnosis. https://www.who.int/topics/anaemia/en 
[14] Sousa, A.C.P.A., Dias, R.C., Maciel, A.C.C. and Guerra, R.O. (2012) Frailty Syndrome and Associated Factors in Community-Dwelling Elderly in Northeast Brazil. Archives of Gerontology and Geriatrics, 54, 95-101. https://doi.org/10.1016/j.archger.2011.08.010

[15] Lustosa, L.P, Pereira, D.S., Dias, R.C., Britto, R.R., Parentoni, N.A. and Pereira, L.S.M. (2011) Translation and Cultural Adaptation of the Minnesota Leisure Time. Geriatria \& Gerontologia, 5, 57-65.

https://s3-sa-east-1.amazonaws.com/publisher.gn1.com.br/ggaging.com/pdf/v5n2a0 3.pdf

[16] Leopoldino, A.A.O. (2016) Fragility, Comorbidities, Pain Intensity, Disability and Quality of Life in Students with Acute Hypermobility: Data from the Back Complaints in the Elders study (BACE). Doctoral Thesis, Federal University of Minas Gerais, Belo Horizonte.

[17] Vieira, R.A., Guerra, R.O., Giacomin, K.C., Vasconcelos, K.S.S., Andrade, A.C.S.A., Pereira, L.S.M., Dias, J.M.D. and Dias, R.C. (2013) Prevalence of Frailty and Associated Factors in Community-Dwelling Elderly in Belo Horizonte, Minas Gerais State, Brazil: Data from the FIBRA Study. Cadernos de Saúde Pública, 29, 1631-1639. https://doi.org/10.1590/S0102-311X2013001200015

[18] Lourenço, R.A., Guedes, D.V., Moreira, V.G., Delgado, F.E.F., Atalaia, K., Banhato, E. and Mármora, C.H.C. (2019) Prevalence of Frailty and Associated Factors in a Community-Dwelling Older People Cohort living in Juiz de Fora, Minas Gerais, Brazil: Fibra-JF Study. Ciência \& Saúde Coletiva. 24, 35-44. https://doi.org/10.1590/1413-81232018241.29542016

[19] Calado, L.B. (2013) Aspects of Frailty Syndrome in the Elderly in Ribeirão Preto. Master's Project, Ribeirão Preto Medical School, Ribeirão Preto.

[20] Alvarado, B.E., Zunxunegui, M.V., Béland, F. and Bamvita, J.M. (2008) Life Course Social and Health Conditions Linked to Frailty in Latin American Older Men and Women. The Journals of Gerontology, 63A, 1399-1406. https://doi.org/10.1093/gerona/63.12.1399

[21] Buffon, P.L.D., Sgnaolin, V., Engroff, P., Viegas, K., Carli, G.A. (2015) Prevalence and Characterization of Anemia in Elderly Served by the Family Health Strategy. Revista Brasileira de Geriatria e Gerontologia, 18, 373-384. https://doi.org/10.1590/1809-9823.2015.14033

[22] Santos, I.S., Scazufca, M., Lotufo, P.A., Menezes, P.R. and Benseñor, I.M. (2012) Anemia and Dementia among the Elderly: The São Paulo Ageing \& Study. International Psychogeriatrics, 24, 74-81. https://doi.org/10.1017/S1041610211001724

[23] Silva, C.L.A., Lima-Costa, M.F., Firmo, J.O.A. and Peixoto, S.V. (2012) Hemoglobin Level in Older Adults and the Association with Nutritional Status and Use of Health Services: The Bambuí Project. Cadernos de Saúde Pública, 28, 2085-2094. https://doi.org/10.1590/S0102-311X2012001100008

[24] Silva, J.C., Moraes, Z.V., Silva, C.A., Mazon, S.B., Guariento, M.E., Neri, A.L. and Fattori, A. (2014) Understanding Red Blood Cell Parameters in the Context of the Frailty Phenotype: Interpretations of the FIBRA (Frailty in Brazilian Seniors) Study. Archives of Gerontology and Geriatrics, 59, 636-641. https://doi.org/10.1016/j.archger.2014.07.014

[25] Haslam, A., Hausmam, D.B., Davery, A., Cress, M.E., Johnson, M.A. and Poon, L.W. (2012) Associations of Anemia and Physical Function in Georgia Centenarians. Journal of the American Geriatrics Society, 60, 2362-2363. 
https://doi.org/10.1111/jgs.12009

[26] Coelho, F.M., Pereira, D.S., Lustosa, L.P., Silva, J.P., Dias, J.M.D., Dias, R.C.D., Queiroz, B.Z., Teixeira A.L., Teixeira, M.M. and Pereira, L.S.M. (2012) Physical Therapy Intervention (PTI) Increases Plasma Brain-Derived Neurotrophic Factor (BDNF) Levels in Non-Frail and Pre-Frail Elderly Women. Archives of Gerontology and Geriatrics, 54, 415-420. https://doi.org/10.1016/j.archger.2011.05.014

[27] Pegorari, M.S. and Tavares, D.M.S. (2014) Factors Associated with the Frailty Syndrome in Elderly Individuals Living in the Urban Area. Revista Latino-Americana de Enfermagem, 22, 874-882.

https://doi.org/10.1590/0104-1169.0213.2493

[28] Tavares, D.M.S., Almeida, E.G., Ferreira, P.C.S., Dias, F.A. and Pegorari, N.S. (2014) Fragility Status among Elderly with Indicative of Depression by Gender. Jornal Brasileiro de Psiquiatria, 63, 347-353. https://doi.org/10.1590/0047-2085000000044 